\title{
Continuity between Fetal and Neonatal Neurobehavior
}

\author{
Milan Stanojevic, Asim Kurjak \\ Department of Obstetrics and Gynecology, Medical School University of Zagreb, Sveti Duh General Hospital, Zagreb, Croatia \\ Correspondence: Dr. Milan Stanojevic, Department of Obstetrics and Gynecology, Medical School University of Zagreb, Sveti \\ Duh General Hospital, Sveti Duh 64, 10000 Zagreb, Croatia \\ e-mail: milan.stanojevic@ kc.t-com.hr
}

\begin{abstract}
As the development of the brain is unique and continuing process throughout the gestation and after birth, it is expected that there is also continuity of fetal and neonatal movements which are the best functional indicator of developmental processes of the brain. Understanding the relation between fetal and infant behavior and developmental processes of the brain in different periods of gestation may make achievable the distinction between normal and abnormal brain development. Epidemiological studies revealed that many neurologically impaired infants belong to low risk population, which means that they seemed to be developmentally normal as fetuses and as infants, while later childhood neurological disability was diagnosed. Which methods of neurological assessment are available for that purpose? Prenatally we have not many possibilities for neurological assessment, while postnatally the repertoire of diagnostic possibilities is increasing. A mong the postnatally available methods for neurological assessment, the most important are: clinical neurological assessment, neuroimaging methods, assessment of general movements (GMs) and combinations. Postnatal neurological assessment is probably easier to perform than prenatal, by using a simple and suitable for everyday work screening clinical test with good reliability, specificity and sensitivity.

There is a possibility for the early and simple neurological assessment of the term and preterm newborns with the aim to detect associated risks and anticipate long-term outcome of the infant, and to establish a possible causative link between pregnancy course and neurodevelopmental outcome. The evaluation of infant's developmental optimality should be assessed in order to investigate whether the infant is neurologically normal or damaged. N eurological assessment at term by A miel-Tison (A TNAT) is taking into account neurological maturation exploring so called lower subcortical system developing earlier from the reticular formation, vestibular nuclei and tectum, and upper cortical system developing from the corticospinal pathways.

Conventional acquisition neuroimaging techniques together with modern diffusion neuroimaging techniques can identify typical patterns of brain injury, even in the early course of the disease. How ever, even though highly suggestive, these patterns cannot be considered as pathognomonic. N evertheless neuroimaging methods alone are not sufficient to predict the neurological outcome in neonates from highrisk population.
\end{abstract}

Prechtl stated that spontaneous motility, as the expression of spontaneous neural activity, is a marker of brain proper or disturbed function. The observation of unstimulated fetus or infant which is the result of spontaneous behavior without sensory stimulation is the best method to assess its central nervous system capacity. A ll endogenously generated movement patterns from un-stimulated central nervous system could be observed as early as from the 7-8 weeks of postmenstrual age, with developing a reach repertoire of movements within the next two or three w eeks, continuing to be present for 5 to 6 months postnatally. This remarkable fact of the continuity of endogenously generated activity from prenatal to postnatal life is the great opportunity to find out those high-risk fetuses and infants in whom development of neurological impairment is emerging. The most important among those movements are GM sinvolving the whole body in a variable sequence of arm, leg, neck and trunk movements, with gradual beginning and the end. They wax and wane in intensity, force and speed being fluent and elegant with the impression of complexity and variability. A ssessment of GM s in high-risk newborns has significantly higher predictive value for later neurological development than neurological examination. K urjak and co-workers conducted a study by 4D ultrasound and confirmed earlier findings made by 2D ultrasonography, that there is behavioral pattern continuity from prenatal to postnatal life. A ssessment of neonatal behavior is a better method for early detection of cerebral palsy than neurological examination alone.

A re we approaching the era when there will be applicable neurological test for fetus and assessment of neonate will be just the continuation? This is still not easy question to answer, because even postnatally there are several neurological methods of evaluation, while in utero we are dealing with more complicated situation and less mature brain. Could neonatal assessment of neurologically impaired fetuses bring some new insights into their prenatal neurological status is still unclear and to be investigated. New scoring system for prenatal neurological assessment of the fetus proposed by Kurjak et al will givesome new possibilities to detect fetuses at high neurological risk, although it is obvious that dynamic and complicated process of functional CNS development is not easy to investigate.

The aim of this review is to present continuity of the functional central nervous system assessment from prenatal to postnatal life.

Keywords: Fetal neurology, neonatal neurology, continuity, cerebral palsy. 


\section{INTRODUCTION}

For centuries human brain was a black inaccessible box full of mysteries and uncertainties. Physicians were just able to observe outcomes of different pathological processes in the brain sometimes expressed as a neurological disease or disability, while in some psychiatric diseases the brain was anatomically normal, although there was no doubt that the patient was sick. $W$ ith the development of embryology, physiology, and sophisticated imaging, electrophysiological, genetic and other methods, we are becoming aware of some processes taking place in the brain important for the development of every human being. ${ }^{1} \mathrm{U}$ Itrasound technology and its prenatal and postnatal application in the evaluation of the development of the central nervous system (CNS) can be interpreted only in contrast with the structural developmental events in the particular period of gestation and development. ${ }^{1}$ Thus, understanding the relation between fetal and infant behavior and developmental processes in different periods of gestation may make achievable the distinction between normal and abnormal brain development, as well as the early diagnosis of various structural or functional abnormalities. ${ }^{1-3}$

Development of human brain is not completed at the time of delivery and even years afterwards. ${ }^{1-3}$ In an infant born at term, characteristic cellular layers can be observed in motor, somatosensor, visual and auditory cortical areas. ${ }^{1-3}$ While proliferation and migration are completed in a term infant, synaptogenesis, neuronal differentiation and myelination continue very intensively. ${ }^{1-3}$ The developmental processes of the brain are so complex and the possibility for their impairment is very high, which is the reason why congenital malformations of the brain are among the most frequent. $B$ rain is very sensitive to any kind of prenatal or postnatal injury, which may result in developmental disorders. ${ }^{1} \mathrm{M}$ ost of the injuries occur during pregnancy, while intrapartal and postanatal brain injuries are not so frequent. ${ }^{1}$ Therefore it is reasonable to make an effort to diagnose fetuses with brain damage, which is very chal lenging task prompting the development of fetal neurology. As the development of the brain is unique and continuing process throughout the gestation and after birth, it is expected that there is also continuity of fetal and neonatal movements which are the best functional indicator of developmental processes of the brain. $^{1-3}$

The aim of this review is to present continuity of the general and other movements from prenatal to postnatal life.

\section{NEUROLOGICAL DISABILITY FROM PRENATAL TO POSTNATAL LIFE}

As it could be learned from fetuses with structurally or functionally abnormal brain, their neurodevelopmental status is disturbed pre- and postnatally. ${ }^{4}$ A mong other fetuses we are able to define those who are at neurological risk, among whom we are searching for those who will have developmental disability. Epidemiological studies revealed that many neurologically impaired infants belong to low risk population, which means that they seemed to be developmentally normal as fetuses and as infants, while later childhood neurological disability was diagnosed. ${ }^{5}$ Dyskinetic cerebral palsy (CP) is the dominant type of CP found in term-born, appropriate-forgestational-age children with severe impairments who have frequently experienced adverse perinatal events. ${ }^{5}$ As neuroprotective methods of treatment are available for some infants, simple screening methods could be helpful to detect impaired fetuses early enough in order to avoid developmental catastrophe. ${ }^{6,7}$

The most infants will be diagnosed as having $C P$, heterogeneous group of disorders in which sometimes even hereditary elements could be found. ${ }^{8}$ Parents of one child with CP had a 4,8-fold risk of having a second affected child, and where the siblings were twins, the risk was 29 -fold. ${ }^{8}$ These familial risks were particularly high in some clinical subgroups: 17-25 in singletons and 37-155 in twins, including hemiplegia, diplegia and quadriplegia. ${ }^{8}$ The remarkably high familial risks are difficult to explain without some contribution of heritable factors. ${ }^{8} \mathrm{CP}$ is the commonest cause of severe childhood disability, the etiology of which is largely unknown. ${ }^{8}$ It is an "umbrella" term for disorders of development, movement and posture, resulting in limitations of activity due to nonprogressive impairment of developing brain. ${ }^{9}$ The diagnosis of $\mathrm{CP}$ is retrospective and it is exceptionally made before the age of 6 months in only most severely affected infants, and the specificity of the diagnosis will improve as the child ages and the nature of the disability evolves. ${ }^{10} \mathrm{CP}$ does not result from a single event but rather there is a sequence of interdependent adverse events providing to the condition. ${ }^{11,12}$ This time frame of evolving adverse events is something which should be taken into account when considering the possibility of $\mathrm{CP}$ diagnosis in infants. ${ }^{10,11,12}$ The understanding of the profile of a child's disability across multiple domains is an ongoing process necessary for appropriate treatment and future planning. ${ }^{10}$ This theoretical statement is sometimes very difficult to be practically implemented. A $n$ attempt to make early diagnosis of CP should be followed with factors related to pathogenesis, impairment and functional limitations in every patient. ${ }^{10}$

The decreasing trend from the period 1991-1994 continued, both in children born at term and especially in those born preterm. ${ }^{5,10}$ However, the increase in dyskinetic CP in children born at term was a matter of concern. ${ }^{10}$ In this group, a perinatal hypoxic ischemic encephalopathy had been present in $71 \%$. Spastic hemi plegia, dipl egia and tetraplegia accounted for $38 \%$, $35 \%$ and $6 \%$, respectively, dyskinetic cerebral palsy for $15 \%$, and ataxia for $6 \% .{ }^{10}$ There was a further increase in full-term dyskinetic CP. ${ }^{10}$ The origin of $\mathrm{CP}$ in children born at term was considered to be prenatal in 38\%, peri/neonatal in 35\% and 
unclassifiable in $27 \%$, while in children born preterm it was $17 \%, 49 \%$ and $33 \%$, respectively. ${ }^{5,10}$

\section{NEONATAL ASPECT OF FETAL NEUROLOGY- CLINICAL POINT OF VIE W}

A lthough we have very powerful imaging and other methods to find out the consequences of the brain damage, there is no doubt that clinical methods like the history and clinical assessment are of utmost importance. There are some recently published data concerning hereditary factors involved in the pathogenesis of CP. ${ }^{8}$ For parents who had had one affected child the risk of recurrence of CP in another child was considerably increased. ${ }^{8}$ In order to identify pathogenesis of the process, neuroimaging methods could be used, among which cranial ultrasound (US), magnetic resonance imaging (MRI), magnetic resonance spectroscopy and diffusion weighted imaging are the most frequently used in very low birth-weight premature infants and in term infants with encephalopathy. ${ }^{10,13}$ Impairment of organs or systems by clinical assessment of muscle tone, strength, and control of voluntary movements for early detection of infants with the risk for CP has been frustrating, because $43 \%$ of 7-year-old children with CP had a normal newborn neurological examination. ${ }^{14}$ Is it possible to change this discouraging fact resulting form our failure to diagnose neurological impairment early enough to intervene? Interests in diagnosis of neurological impairment among ultrasonographers using 4D US have been recently shifted toward prenatal period. ${ }^{15,16} \mathrm{M}$ ost clinicians are aware that in $39,6 \%$ of $C P$ cases, no risk factor could be identified, while it was estimated that solely intrapartum risk factors were present in $24,7 \%$ of CP cases. ${ }^{17}$ The only significant perinatal risk factor was neonatal weight of less than 2500 grams. ${ }^{17}$ A re we approaching the era of the development of diagnostic tests to detect non-reassuring fetal status in its intrauterine life to intervene at appropriate time in order to decrease the $C P$ rate? ${ }^{17}$ This question seems very futuristic because clinicians have a lot of difficulties to detect $C P$ in less than six month old infants. ${ }^{15}$ Is there any possibility to improve timing of postnatal diagnosis of neurological ly disabled infant? Postnatal assessment is probably easier to perform than prenatal, by using a simple and suitable for everyday work screening clinical test with good reliability, specificity and sensitivity. ${ }^{15}$ Such tests are still not widely used, while those complicated and time consuming are used mostly for clinical research purposes. There is a possibility for the early and simple neurological assessment of the term and preterm newborns with the aim to detect associated risks and anticipate long-term outcome of the infant, and to establish a possible causative link between pregnancy course and neurodevelopmental outcome. ${ }^{18}$ A S CP is a disorder of movement and postural control resulting in functional limitations, its diagnosis could be helpful in detection of early impairment. ${ }^{10} \mathrm{Clinical}$ neurological assessment proposed and practiced by A miel-Tison could be very useful in the early detection of newborns at risk. ${ }^{18}$ As al ready mentioned, development of central nervous system (CNS) is very complex and long-lasting process. Therefore the evaluation of its developmental optimality should be assessed in order to investigate whether the infant is neurologically normal or damaged. N eurological assessment at term by A mielTison (ATNAT) is taking into account neurological maturation exploring so called lower subcortical system devel oping earlier from the reticular formation, vestibular nuclei and tectum, and upper cortical system developing from the corticospinal pathways. ${ }^{18,19}$ The role of lower system is to maintain posture against gravity, while the upper system is responsible for the control of erect posture and for the movements of the extremities. ${ }^{19}$ At the corrected age of 40 gestational weeks optimality assessment consists of: head circumference measurement, assessment of cranial sutures, visual pursuit, social interaction, sucking reflex, raise-to-sit and reverse, passive tone in the axis, passive tone in the limbs, fingers and thumbs outside the fist, and autonomic control during assessment. ${ }^{19}$ The A T NA T is increasing accuracy in assessing CNS function in the neonate by using simple scoring system, focusing on the most meaningful items, promoting a clinical synthesis at term, for term and preterm infants. ${ }^{19}$ It was recognized that clinico-anatomic correlations using high resolution neuroimaging techniques could be helpful in the neurological assessment of newborns, while the neurological examination and the functional assessment of the developing CNS are bringing a new perspective of CNS status in neonatal period. ${ }^{20} \mathrm{~A}$ ccording to the investigation of very low birth weight infants, A TNA T at 40 weeks had a positive predictive value of $33 \%$ and negative predictive value of $88 \%$, respectively, with similar results for neurodevelopmental assessment at the age of three months. ${ }^{21}$ This means that we still need some other methods to be used in order to predict neurodevelopmental outcome of low and high risk infants.

\section{NEONATAL ASPECT OF FETAL NEUROLOGY - NE UROIMAGING}

Conventional acquisition neuroimaging techniques together with modern diffusion neuroimaging techniques can identify typical patterns of brain injury, even in the early course of the disease. ${ }^{22}$ However, even though highly suggestive, these patterns cannot be considered as pathognomonic. Diffusion techniques can hel $p$ to differentiate different types of diffuse brain edema. ${ }^{22}$

U Itrasound has been very important diagnostic modal ity for the detection and follow-up of central nervous system disorders of sick premature and term babies in the neonatal intensive care units for many years. ${ }^{23-26}$ It has fairly acceptable sensitivity and specificity in high and low risk neonatal population. The validity of the two dimensional ultrasound (2D US) scans was 85\%, sensitivity $70 \%$, specificity $90 \%$, positive predictive value $72 \%$ 
and negative predictive value $89 \%$, respectively. ${ }^{27}$ The $2 \mathrm{D}$ US scans classified as low-risk were followed by a normal neurological outcome in 74 (89\%) of 83 infants; those classified as high-risk for neurological impairment were followed by abnormal neurological outcome in 21 (72\%) of 29 infants. ${ }^{27}$ Other neuroimaging procedures like MRI or computed tomography (CT) are also available and feasable in neonatal period with better sensitivity and specificity for the detection of hypoxic ishemic encephalopathy or focal cortical damage, but ul trasound remains as very important screening method for depiction of fetal and neonatal brain. ${ }^{22,28} \mathrm{~N}$ euroimaging is particularly useful to determine the timing of hypoxic-ischemic brain damage ${ }^{29} \mathrm{Cranial}$ ultrasound has been used to determine the type and evolution of brain damage. $M$ agnetic resonance imaging (MRI) and computed tomography (CT) of the head have also been used to detect antenatal, perinatal and neonatal abnormalities and timing on the basis of standardized assessment of brain maturation. ${ }^{29}$ In term and near term neonates with $C P$, head MRI and CT revealed focal arterial infarction in $22 \%$, brain malformations in $14 \%$, periventricular white matter abnormalities in $12 \%$, generalized brain atrophy in $7 \%$, hypoxicishemic brain injury in $5 \%$, intracranial hemorrhage in $5 \%$, delayed myelination in $2 \%$, other abnormality in $6 \%$, while in $37 \%$ of infants neuroimaging findings were normal. ${ }^{13}$

A lthough three-dimensional (3D) neurosonography is safe and low-risk procedure in the neonate, due to a very limited availability of equipment for 3D neurosonography, which is often connected with the necessity of newborn transportation, benefits and risks of 3D imaging should be taken under consideration. ${ }^{30-32}$ In the institutions where equipment is available and can be transported to the patient, it is method of choice for the depiction of neonatal brain. ${ }^{30-37}$ Indications for $3 \mathrm{D}$ neurosonography in newborn period are the same as for $2 D$, and whenever $2 D$ is unreliable or doubtful, than $3 D$ is indicated. The main indications for 3D neurosonography in the newborn period are prenatally or postnatally developed: $30-37$

- Intracranial hemorrhage,

- Hypoxic-ischemic brain damage,

- Inflammatory disorders of the brain and its complications,

- Ventriculomegaly and hydrocephaly (Doppler and volumetric studies included),

- Congenital brain defects, and

- A ssessment of gestational age.

$M$ any known and unknown perinatal and social risk factors can influence the development of neonatal brain especially in premature infants, although abnormal prenatal neurosonography or postnatal neurological findings in apparently well neonates can prompt neonatologists to search for ultrasound abnormalities. ${ }^{17,38} \mathrm{~A}$ good correlation was found between ultrasound findings in the fetal and neonatal period and signs of neurological impairment in the neonatal period and later in childhood. ${ }^{15,18,38} \mathrm{Cranial}$ ultrasound can be a good predictor of disabling and non-disabling CP at the age of two years in low birth weight infants and it can be in relation with impaired motor function in five-year-old children. ${ }^{24,39}$ Improving survival of very low birth weight infants contributed to the increased incidence of CP despite introduction of sophisticated treatment methods of intensive care. ${ }^{24} \mathrm{~B}$ rain lesions of the white matter diagnosed by ultrasound were found to be a powerful predictor of disabling CP. ${ }^{24} \mathrm{~N}$ everthel ess neuroimaging methods al one are not sufficient to predict the neurological outcome in neonates from high risk population. There is need for more precise clinical and neuroimaging methods applicable in every day practice, in order to improve clinicians' ability to detect neurological handicap as early as possible and initiate treatment. ${ }^{7}$

\section{GENERAL MOVEMENTS}

In the last thirty years objective assessment of videotaped general movements by Precht's method has been shown to be predictive of later CP. ${ }^{40}$ The quality of general movements (GM s) at 2 to 4 months post-term (so-called fidgety GM age) has been found to have highest predictive value in the detection of the infants at risk for CP development. ${ }^{41}$ It seems that assessment of the quality of $\mathrm{GM}$ is a window for early detection of children at high risk for devel opmental disorders. ${ }^{41} \mathrm{M}$ ethod is simple and it is based on so called "Gestalt perception" i.e. evaluation of GM complexity, variation and amplitude. ${ }^{40,41}$ A ssessment of GM s at 2 to 4 months post-term at so called fidgety $\mathrm{GM}$ age has been found to have the highest predictive value for development of $\mathrm{CP}$, if abnormal. ${ }^{40,41}$

Heinz Prechtl's work enabled that spontaneous motility during human development has been brought into focus of interest of many perinatologists prenatally and developmental neourologists postnatally. ${ }^{40,42}$ A ccording to the research preceding Prechtl's ingenious idea, during the development of the individual the functional repertoire of the devel oping neural structure must meet the requirements of the organism and its environment. ${ }^{40}$ This concept of ontogenetic adaptation fits excellently to the development of human organism, which is during each developmental stage adapted to the internal and external requirements. ${ }^{40}$ Prechtl stated that spontaneous motility, as the expression of spontaneous neural activity, is a marker of brain proper or disturbed function. ${ }^{40,41}$ The observation of unstimulated fetus or infant which is the result of spontaneous behavior without sensory stimulation is the best method to assess its central nervous system capacity. ${ }^{40}$ All endogenously generated movement patterns from un-stimulated central nervous system could be observed as early as from the 7-8 weeks of postmenstrual age, with developing a reach repertoire of movements within the next two or three weeks, continuing to be present for 5 to 6 months postnatally. ${ }^{43}$ This remarkable fact of the continuity of endogenously generated activity from prenatal to postnatal life is the great opportunity to find out those high risk fetuses and infants in whom development of 
neurological impairment is emerging. The most important among those movements are so called general movements (GM s) involving the whole body in a variable sequence of arm, leg, neck and trunk movements, with gradual beginning and the end. ${ }^{40-43}$ They wax and wane in intensity, force and speed being fluent and elegant with the impression of complexity and variability. ${ }^{40-43} \mathrm{GM} \mathrm{s}$ are called fetal or preterm from 28 to 36 to 38 weeks of postmenstrual age, while after that we have at least two types of movements: writhing present to 46 to 52 weeks of postmenstrual age and fidgety movements present till 54 to 58 weeks of postmenstrual age. ${ }^{40-43}$ Lack of fluency and existence of considerable variation and complexity are the main characteristics of mildly abnormal GM s. ${ }^{44}$ When complexity, variation and fluency are absent, than we are dealing with definitely abnormal GM s. ${ }^{44}$

The quality of each individual movement includes speed, amplitude and force combined in one complex perception. ${ }^{40-45}$ Investigation of normal and neurologically impaired preterm infants showed that except for higher incidence of cloni in the abnormal group, there was no marked difference in the quantity of different motor patterns studied. ${ }^{45,46} \mathrm{H}$ owever, video analysis of another group of sick preterm infants revealed a "reduction of elegance and fluency as well as variability, fluctuation in intensity and speed rather than any change in incidence of distinct motor patterns". ${ }^{45-47} \mathrm{~B}$ ased on postnatal studies, it would be very important to seek for abnormal quantity and quality of prenatal movements in order to find fetuses neurologically at risk. ${ }^{47}$

Some facts are very important in the assessment of GM s. The first is that evaluation of GM s should be based on the video recorded movements either pre- or postnatally. The second fact is that when assessing GM s one should use so called "gestalt perception", which could be described as overall impression of GM s with standardized procedure. ${ }^{40}$ D uring the perception one should recognize the movement patterns of GM s, than assess their complexity, variability and fluency. ${ }^{40,41}$ A ccording to Hadders-A Igra, GM s could be classified as normal-optimal, normal-suboptimal, mildly abnormal and definitely abnormal. ${ }^{41}$ This modality of GM assessment is important for the prenatal and postnatal observation of GM s. It is not so important to assess the quantity of GM s, while the assessment of their qual ity is of utmost importance in terms of the prognosis of neurodevelopmental outcome. They can better predict neurodevelopmental outcome than classical neurologic examination al one. ${ }^{48}$

General movements in high risk and disabled neonateslesson for prenatal assessment.

GM s were studied in high risk and disabled neonates with results which are very illustrative for prenatal assessment of GM s in high risk fetuses. In infants with meningomyelocele between days one and seven, tendon leg reflexes caudal to the meningomyelocele had disappeared in al most all neonates. ${ }^{49}$
However, leg movements caudal to the meningomyelocele remained concurrently present with GM s in all neonates after day seven, but their duration decreased when compared with GM s on the day one. ${ }^{49}$ In neonates with spina bifida aperta, leg movements caudal to the meningomyel ocel e concur with GM s, indicating functional neural conduction through the meningomyelocele. ${ }^{49}$ The disappearance of these leg movements is caused by lower motor neuron dysfunction at the reflex arc, while neural conduction through the meningomyelocele is still functional. ${ }^{49}$

The same GM s in children with D own syndrome (DS) were characterized by low to low/moderate speed, large to large/ moderate amplitude, partially creating impression of fluency, smoothness and complexity, abrupt beginning and end, few other concurrent gross movements. ${ }^{50}$ During the 6 months, all children showed an improvement of qualitative and semiquantitative evaluation, but it was possible to observe great heterogeneity among children in the evolutionary course. ${ }^{50} \mathrm{GM} \mathrm{s}$ evaluation of children with not known motor problems was normal, showing only slight and transient abnormalities at first months. ${ }^{50} \mathrm{GM} \mathrm{s}$ character of children with DS could be related to central nervous system and peripheral abnormalities characterizing this syndrome. ${ }^{50}$ The evaluation of GM s in children with DS could be an early marker of motor impairment and hel $p$ in early management decisions making. ${ }^{50}$

The incidence of normal GM s in infants with asymmetric intrauterine grow th retardation (IU GR) was lower than in their appropriate for gestational age-matched controls. ${ }^{51}$ Significant correlations were found between GM quality and neurodevelopmental scores in the IU GR group. ${ }^{51}$ The fidgety movements were the most sensitive and specific for prediction of neurologic outcome at the age of two years. ${ }^{51}$ The GM assessment can serve as an additional tool for examining the neurologic status of the preterm and term IU GR infants..$^{51}$

Psychomotor delay in children of women with epilepsy was confirmed by traditional neurological examination at 7 days, 4 weeks, 13 weeks and 6 months, while between 9 and 12 months of age, traditional neurologic examination became "silent". ${ }^{52}$ GM assessment was found to be a better predictor of psychomotor development than neurological examination. ${ }^{52}$ Psychomotor delay in the offspring of epileptic women could be diagnose by GMS and neurologic evaluation, providing complementary information concerning psychomotor development and later outcome of these children. ${ }^{52}$

For predicting motor outcome of very low birth weight (V LBW ) infants, the assessment of GM has a positive predictive value of $89 \%$ and negative predictive value of $84 \%$; while neurodevelopmental assessment at 40 weeks had a positive predictive value of $33 \%$ and negative predictive value of $88 \%$, respectively, with similar results for neurodevelopmental assessment at age of three months. GM assessment is a simple, 
repeatable and non-intrusive technique, and may be a val uable method for the early detection of central nervous system impairment in V LBW infants. ${ }^{21}$

In conclusion, prenatal and postnatal assessment of GM s according to Prechtl's method gives quite new insight on the function and development of central nervous system. This important modality is time consuming and requires some technology and expertise to be practiced, but advantages of its implementation in prenatal and postnatal life are very promising and encouraging in terms of its prognostic value. Prenatal assessment of GM s is well developed and established, while prenatal assessment needs sophisticated real time 4D ultrasonographic or other technology in order to enable more precise assessment of GM quality in fetuses.

\section{CONTINUITY OF GMS FROM PRENATAL TO POSTNATAL LIFE}

Postnatal studies of neonatal behavior have taught us that the assessment of behavior is a better predictor of neurodevelopmental disability than neurological examination. ${ }^{47}$ It is important to mention that postnatal observation of movement patterns was introduced by Prechtl and coworkers in the way that they have been observing spontaneous movements of the infant using video typing and "off-line" analysis of both quantity and quality of the movement. ${ }^{40,42}$ They proved that assessment of $\mathrm{GM}$ s in high risk new borns has significantly higher predictive value for later neurological development than neurological examination..$^{40,42,47} \mathrm{~K}$ urjak and coworkers conducted a study by $4 \mathrm{D}$ ultrasound and confirmed earlier findings made by $2 \mathrm{D}$ ultrasonography, that there is behavioral pattern continuity from prenatal to postnatal life. ${ }^{53} \mathrm{~A}$ ssessment of neonatal behavior is a better method for early detection of $C P$ than neurological examination alone. ${ }^{54}$ It is being speculated that intrauterine detection of encephalopathy would improve the outcome. A Ithough many fetal behavioral studies have been conducted, it is still questionable whether the assessment of continuity from fetal to neonatal behavior could improve our ability of early detection of brain pathology. Early detection could possibly rise an opportunity to intervene and even prevent the expected damage. ${ }^{7}$ Early intervention programs for preterm infants have a positive influence on cognitive outcomes in the short to medium term. ${ }^{7}$

In our work we observed that there were no movements observed in the fetuses which were not present in neonates (Fig. 1). ${ }^{55,56}$ The most frequent were hand to mouth and hand to face fetal and neonatal movements. $H$ and to mouth and hand to face movements were more frequent in fetuses than in neonates, while all other hand movements were less frequent in neonates than in fetuses. ${ }^{55,56}$

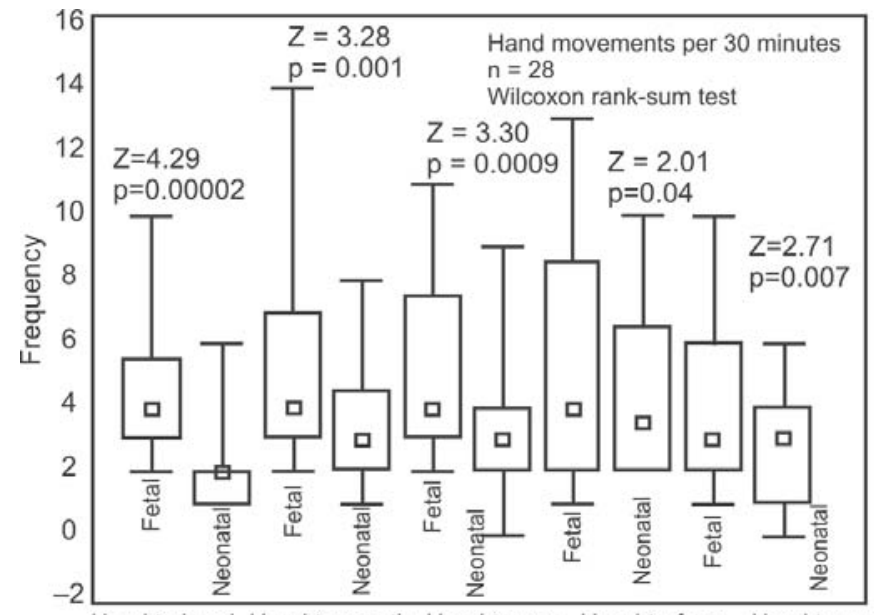

Figs 1: Comparison of hand movement frequency between fetuses in the third trimester of pregnancy and in neonates

$I$ Min-Max
$\square 25 \%-75 \%$
$\square \quad$ Median Value

In our systematic study of fetal behavior by 4D sonography we were able to observe different expressions and movements of fetal face, but the question was if they were indicating fetal awareness? ${ }^{57}$ Is it the facial expression of the fetus that can help in understanding what fetus in utero would like to communicate? A s our recent investigation showed, there is a behavioral continuity from fetal to neonatal life, which probably includes facial expression. ${ }^{55-57}$ We can see on the fetal face whether it is satisfied or unhappy, smiling or worried, selfconfident or uncertain, but is it the expression of fetal face the predictor of its normal neurological development?

Figures 2 to 7 showing continuity of some movements from prenatal to postnatal life.

\section{COULD SOME POSTNATAL SIGNS OF NEUROLOGICAL DISABILITY BE USED PRENATALLY?}

It has been proven by now that ultrasonography is a powerful tool in the assessment of fetal behavior. 4D sonography brought up to light visual observation of the fetus, particularly in two especial ly important domains: fetal finger movements and facial expressions. ${ }^{58,59}$ This new technology is not only a tool of fetal observation but a very useful tool to evaluate the devel opment of fetal CNS in normally developing fetuses and those at high risk. A basic understanding of fetal neurology includes: defining of motor pathways involved, chronology of their maturation and direction of myelination. ${ }^{58,59}$ This information helps clinician in better interpretation of fetal movements. The experience acquired with the Amiel-Tison's Neurological 
A ssessment at Term (ATNAT) helps in interpretation of fetal movements. $15,18,19,60$

The domain of fetal neurology is al ready too extensive, but the focus of interest is mainly second trimester, despite the fact that spontaneous fetal mobility emerges and has al ready became differentiated at a very early age. ${ }^{61}$ This means that period of pregnancy from 20 till 40 weeks of gestation, including the end of the neuronal migration and the post-migratory phase corresponding to the development of neocortex will be taken into consideration. ${ }^{62-64}$

As it was al ready mentioned, CP describes a group of disorders of the devel opment of movement and posture, causing activity limitations, which are attributed to non-progressive disturbances occurring at the time of fetal brain development. ${ }^{65-68}$

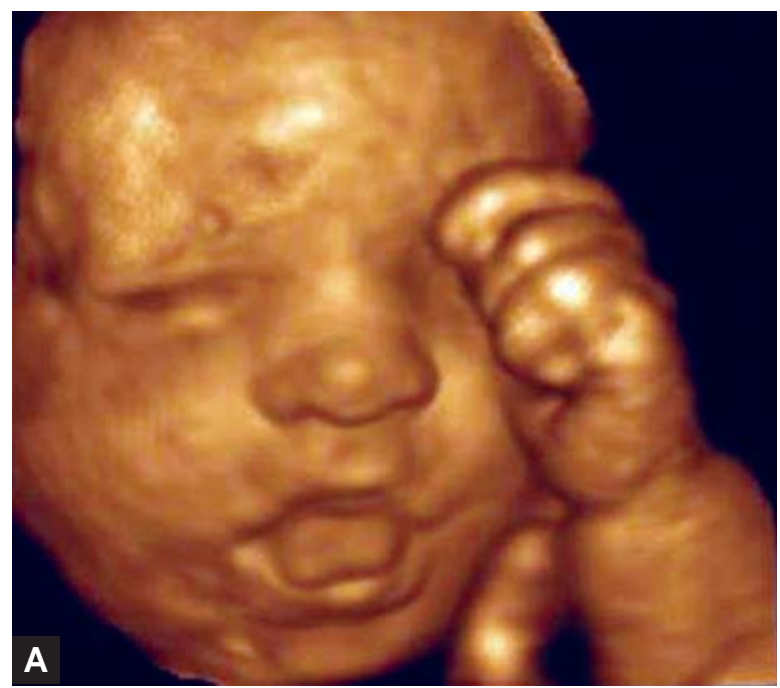

M otor disorders which occur in patients with $\mathrm{CP}$ are often accompanied by disturbances of sensation, cognition, communication, perception, behavior, and/or with seizure disorder. ${ }^{65-68}$ "Disturbances" is a term referring to events or processes which in some way influence the expected pattern of brain maturation. ${ }^{60,69}$ It should be emphasized that morphology does not al ways correspond to neurological outcome. ${ }^{15,18,19,60}$ It would be wise to consider long run prognosis, for each specific type of fetal brain damage and make appropriate decisions for management. $^{7}$

Hopes have been headed towards M R, but in many cases brain changes can not be detected as early as in the first year of life, like for example pathological gliosis which causes secondary hypomyelination. ${ }^{15,18,19,60}$

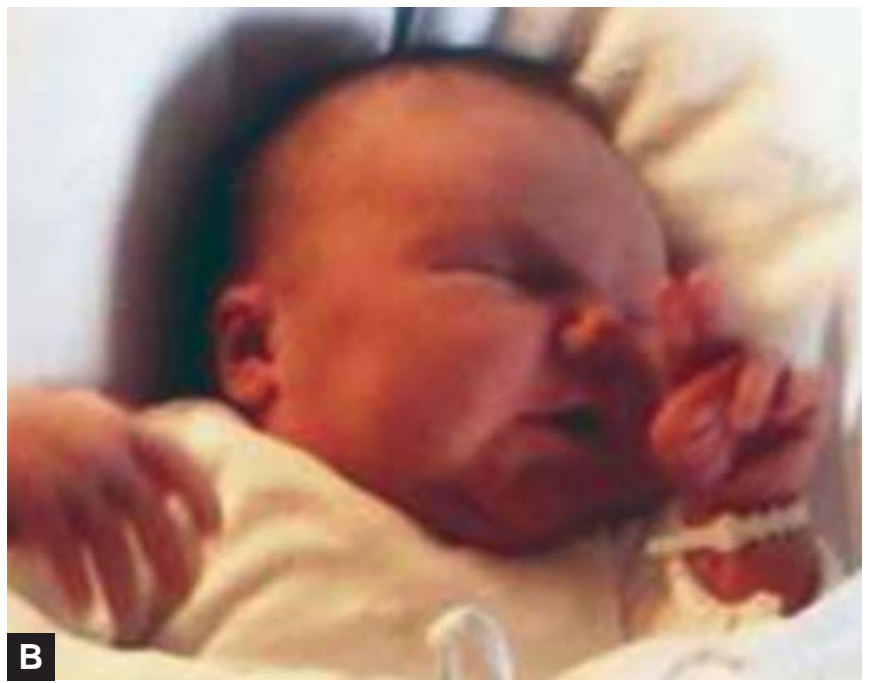

Figs 2A and B: Hand to eye movement: (A) Fetus (3D ultrasound) (B) Neonate
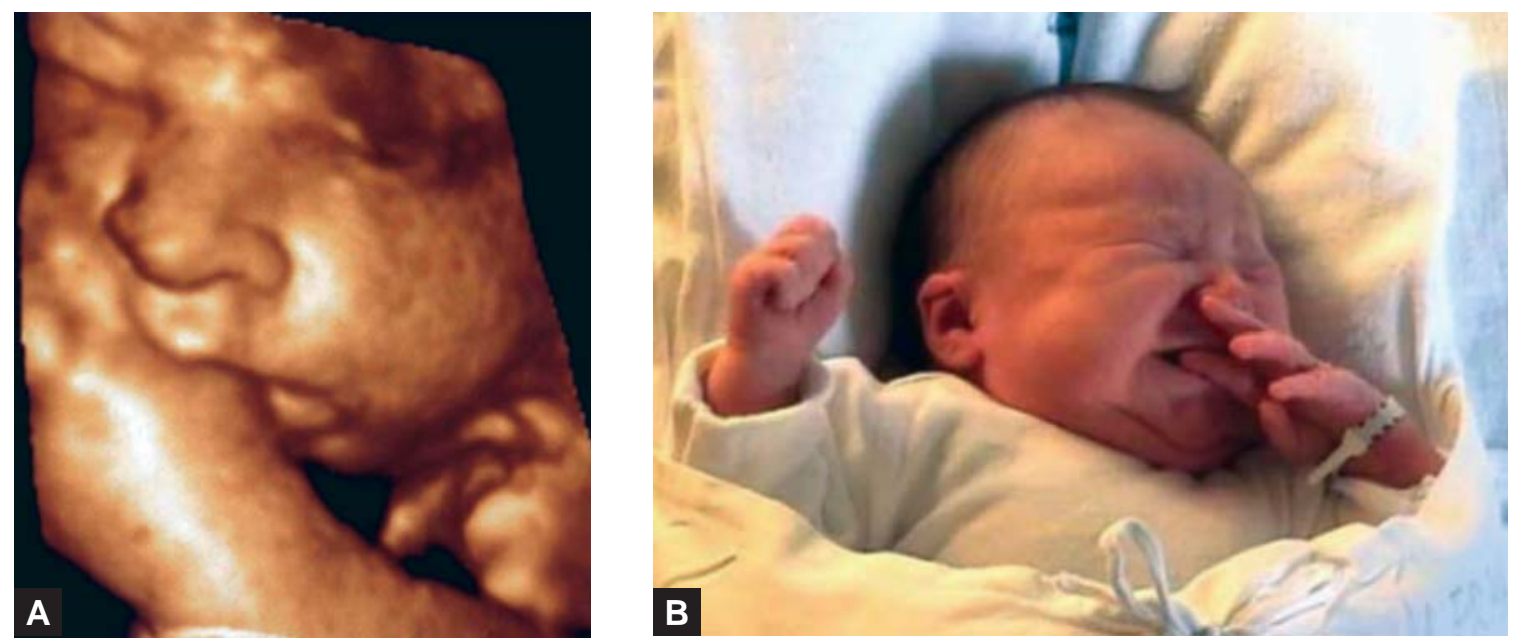

Figs 3A and B: Hand to mouth movement: (A) Fetus (3D ultrasound), (B) Neonate 

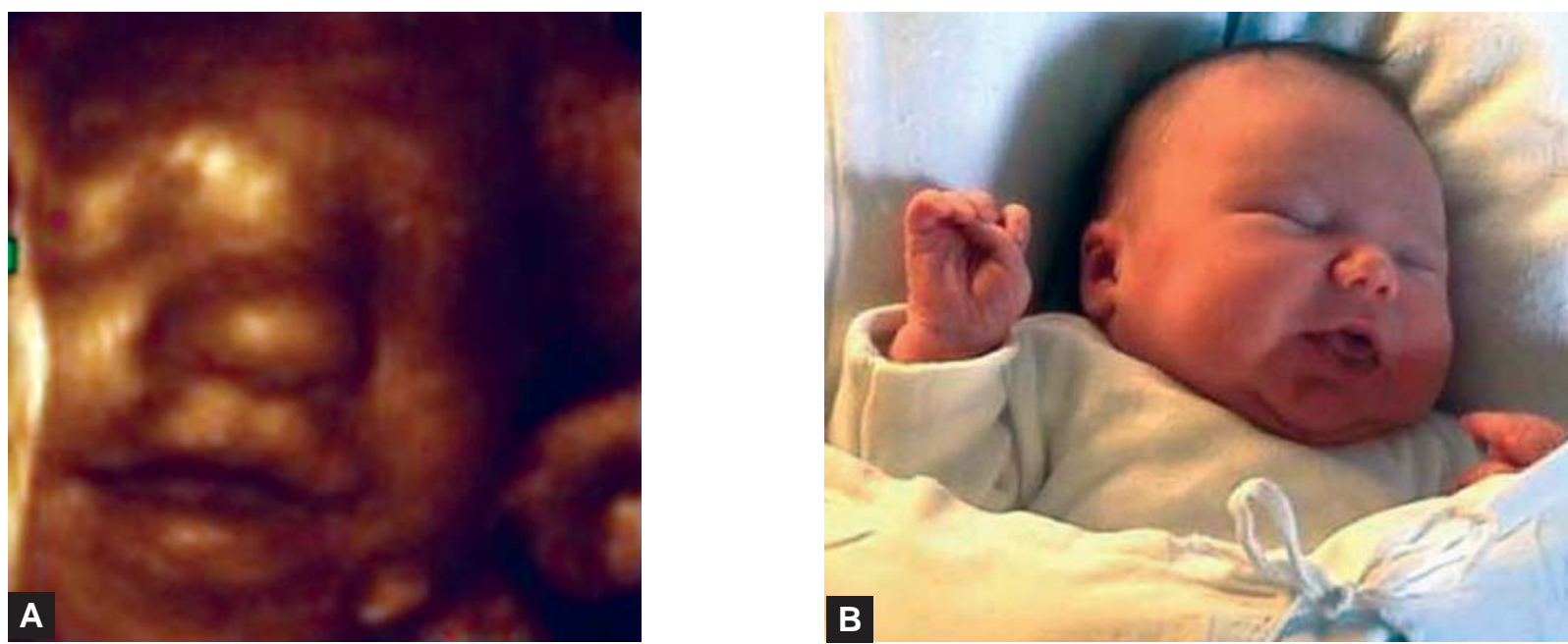

Figs 4A and B: Smiling: (A) Fetus (3D ultrasound) (B) Neonate
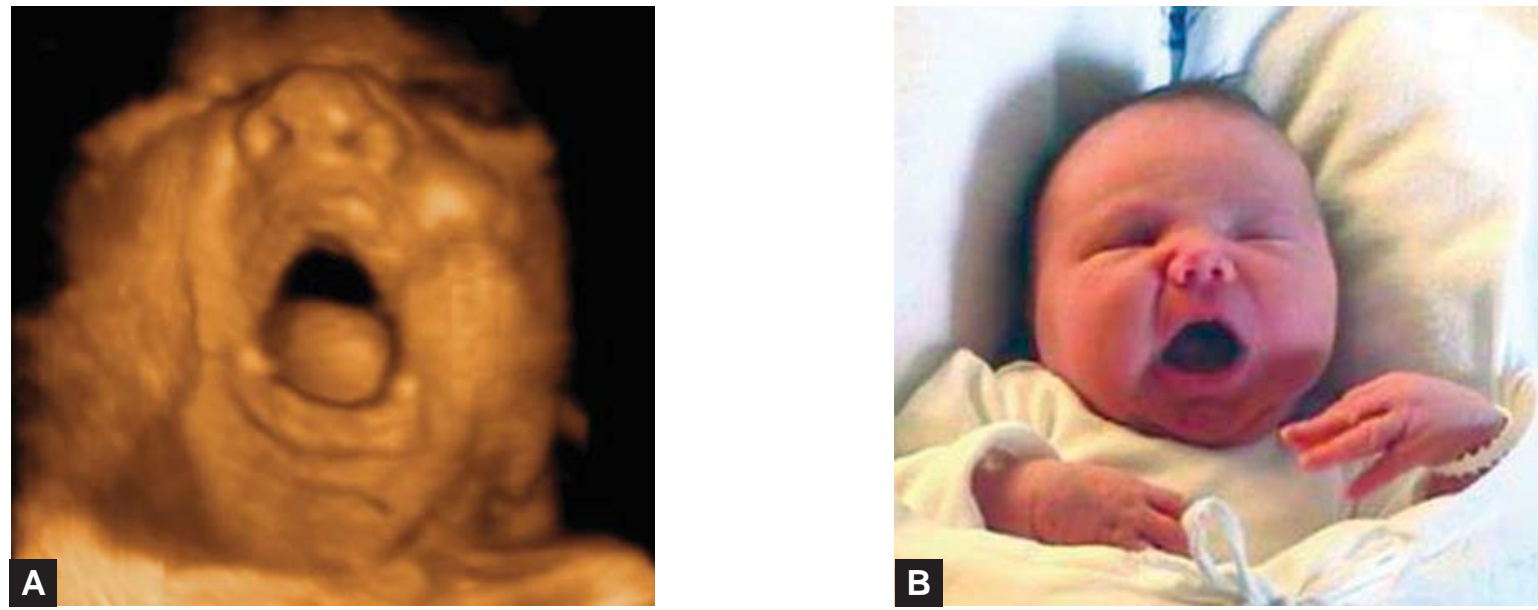

Figs 5A and B: Yawning: (A) Fetus (3D ultrasound) (B) Neonate
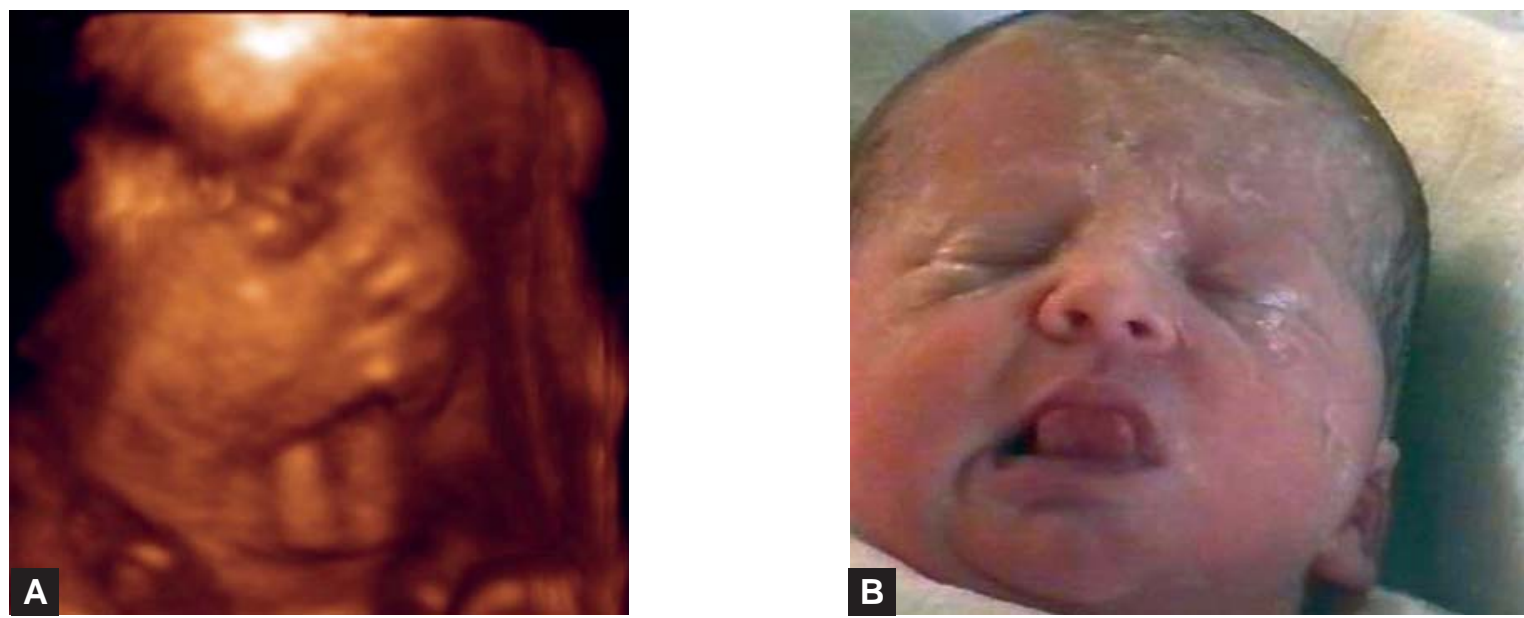

Figs 6A and B: Tongue expulsion: (A) Fetus (3D ultrasound), (B) Neonate 

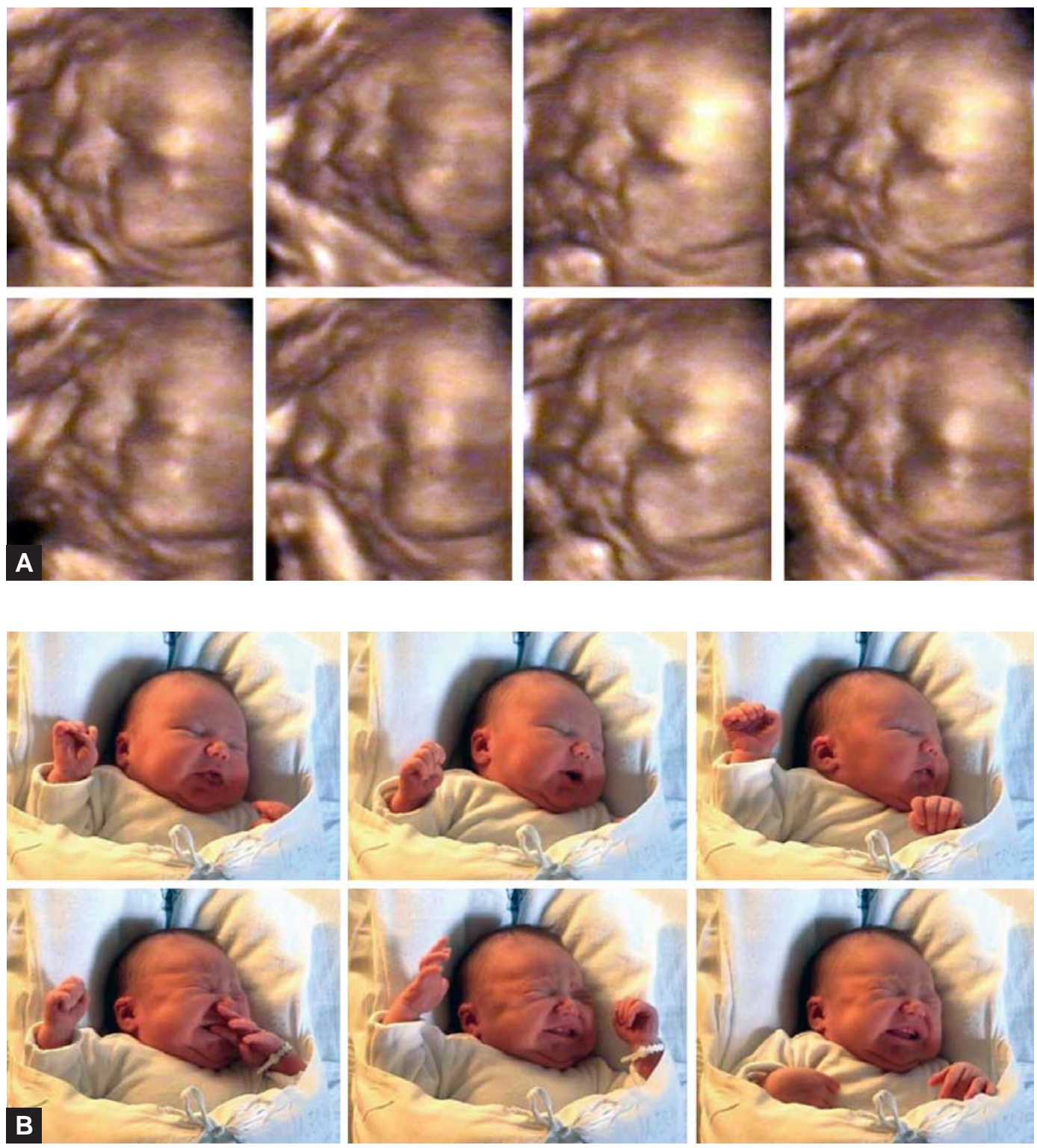

Figs 7A and B: Facial expression: (A) Fetus (3D ultrasound) (b) Neonate

While examining the fetal head by 4D, sonographer should examine bony structures and fetal cranial sutures, if they are folding over one another, it is considered to bee a ominous sign previously described by A miel-Tison. ${ }^{15,18,60}$ The same sign should be searched for postnatally, as a part of neurological examination. ${ }^{15,18,19,60,69}$

The maj ority of pediatricians believe that the main obstacle for early prediction of CP based on a functional observation of the fetus such as visual observation by 4-D sonography, is due to the "precompetent" stage of most of the motor behavior observed in utero. ${ }^{15,18,60,69,70}$ One of the possible signs detected could be high arched palate, described by A miel-Tison, in clinical assessment of the infant nervous system. ${ }^{15,18,19,60,69}$ W hat was believed as prenatally undetectable became visible by 4D ultrasound. Recently, the 3D "reverse face technique" has been described. ${ }^{54,71}$ This technique overcomes shadowing of the fetal face by rotating the frontal facial image through $180^{\circ}$ al ong the vertical axis, so that the palate, nasal cavity and orbits become visualized. ${ }^{54,71}$

Pooh and Ogura examined 65 normal fetuses by 3D/4D. The purpose of their study was to investigate the natural course of fetal hand and finger positioning. ${ }^{72}$ During the $9^{\text {th }}$ and at the beginning of the 10th week fetal hands were located in front of the chest and no movements of wrists and fingers were 
visualized. From the middle of the $10^{\text {th }}$ week, active arm movements were observed. ${ }^{72}$ This study is very important, because it is showing that finger and thumb movements begun in the early stage of human life, long before the maturation of the upper system. ${ }^{69,72}$ Therefore this motor activity depends on the lower system and not before 30-32 weeks switches to the upper control. ${ }^{69}$

A miel-Tison also described so called neurologic thumb squeezed in a fist. Clenched fingers can al so be detected by $4 \mathrm{D}$ sonography, as well as overlapping cerebral sutures. ${ }^{69}$

Head anteflexion becomes visible during $10^{\text {th }}$ and $11^{\text {th }}$ gestational week, according to de V ries and co-workers. ${ }^{62}$ However, the activity of flexor muscles will depend on the upper system since 34 weeks of gestation. The absence of active head flexion explored by the raise-to-sit maneuver is one of the major neurological signs at 40 weeks of gestation. . $^{15,18,19,60,69}$

\section{CONCLUSION}

N eurological assessment of fetus in utero is extremely difficult even having such sophisticated equipment like 4D ultrasound. A s it is well known that quantity of GM s is not so informative and predictive for neurological impai rment, their qual ity should be assessed. "Gestalt perception" of premature GM s we are dealing with in utero and several weeks postanatally are not as predictive for the detection of neurologically abnormal fetuses or new borns as fidgety GM s emerging from 54 to 58 weeks of postmenstrual age. ${ }^{40,41,44}$ Therefore some additional parameters should be added to the prenatal neurological examination in order to improve clinicians' ability to make the distinction between normal and abnormal fetuses or to assess optimality of CNS development. ${ }^{15,18,19,60,69}$ DiPietro states that an emerging consensus recognizes the fact that "fetal neurobehavior reflects the developing nervous system", however we don't know yet the conceptual and methodological strengths and weaknesses of fetal assessments proposed. ${ }^{73} \mathrm{We}$ are hardly ready to predict the neurological outcome in fetuses between two extreme situations, optimal or very abnormal. The predictive value for a favorable outcome of a complete neurobehavioral pattern in fetus as from 22 gestational weeks on should be demonstrated. Possibilities of 4D sonography are demonstrating the prenatal onset of a brain damage, based on morphological and functional signs. There is no doubt that this observation will be helpful, even though that prenatally observed signs are not yet highly predictive due to the brain immaturity, their identification will be at least recognized as a retrospective marker for a prenatal insult. ${ }^{15,18,19,60,69}$

A re we approaching the era when there will be applicable neurological test for fetus and assessment of neonate will be just the continuation? This is still not easy question to answer, because even postnatal ly there are several neurological methods of evaluation, while in utero we are dealing with more complicated situation and less mature brain. Could neonatal assessment of neurologically impai red fetuses bring some new insights into their prenatal neurological status is still unclear and to be investigated. $\mathrm{N}$ ew scoring system for prenatal neurological assessment of the fetus proposed by K urjak et al. will give some new possibilities to detect fetuses at high neurological risk, although it is obvious that dynamic and complicated process of functional CNS development is not easy to investigate. ${ }^{74}$ W e have still a long way to go.

\section{REFERENCES}

1. Schacher S. Determination and differentiation in the development of the nervous system. In Kandel ER, Schwart $J H$. Principles of neural science. 2nd edition. New Y orkA msterdam-Oxford: Elsevier Science Publishing 1985:730-32.

2. Kostovic I. Prenatal development of nucleus basalis complex and related fibre system in man: a hystochemical study. Neuroscience 1986;17:1047-77.

3. Kostovic I. Zentralnervensystem. In Hinrichsen K V (Ed): Humanembryologie. B erlin: Springer-Verlag, 1990;381-448.

4. A hmed B, K urjak A, A ndonotopo W, K henyab N, Saleh N, A I$M$ ansoori Z. Fetal behavioraland structural abnormalities in high risk fetuses assessed by 4D sonography. U Itrasound R ev O bstet Gynecol 2005;5:275-87.

5. Himmelmann K, Hagberg G, Wiklund L M, Eek M N, Uvebrant P. Dyskinetic cerebral palsy: a population-based study of children born between 1991 and 1998. Dev Med Child Neurol 2007;49:246-51.

6. Wyatt JS, Gluckman PD, Liu PY, A zzopardi D, Ballard R, Edwards DA, CoolCap Study Group, et al. Determinants of outcomes after head cooling for neonatal encephalopathy. Pediatrics 2007;119: 912-21.

7. Spittle A J, Orton J, Doyle LW, Boyd R. Early developmental intervention programs post hospital discharge to prevent motor and cognitive impairments in preterm infants. Cochrane D atabase Syst Rev 2007;(2):CD 005495.

8. Hemminki K, Li X, Sundquist K, Sundquist J. High familial risks for cerebral palsy implicate partial heritable aetiology. Paediatr Perinat E pidemiol 2007;21:235-41.

9. Rosenbaum P, Paneth N, Leviton A, Goldstein M, Bax M, Damiano D, Dan B, Jacobsson B. A report: the definition and classification of cerebral palsy A pril 2006. Dev Med Child Neurol 2007;109 (suppl):8-14.

10. Palmer FB. Strategies for the early diagnosis of cerebral palsy. J Pediatr 2004;145:S8-S11.

11. Walstab JE, B ell RJ, Reddihough DS, Brennecke SP, B essell CK, B eischer N A . Factors identified during the neonatal period associated with risk of cerebral palsy. A ust NZJ O bstet Gynecol 2004;44:342-46.

12. Himmelmann K, Hagberg G, B eckung E, Hagberg B, U vebrant $P$. The changing panorama of cerebral palsy in Sweden. IX. Prevalence and origin in the birth-year period 1995-1998. A cta Paediatr 2005;94:287-94.

13. Wu Y W, Croen LA, Shah SJ , N ew man TB, Najjar DV . Cerebral Palsy in a Term Population: Risk Factors and Neuroimaging Findings Pediatrics 2006;118;690-97.

14. Nelson KB, Ellenberg JH. Neonatal signs as predictors of cerebral palsy. Pediatrics 1979;64:225-32. 
15. A miel Tison C, Gosselin J, K urjak A. Neurosonography in the second half of fetal life: a neonatologist point of view. J Perinat $M$ ed 2006;34:437-46.

16. Kurjak A, M iskovic B, A ndonotopo W, Stanojevic M , A zumendi $G, V$ rcic $H$. How useful is $3 D$ and $4 D$ in perinatal medicine?. J Perinat M ed 2007;35:10-27.

17. Gurbuz A, Karateke A, Y ilmaz $U, K$ abaca $C$. The role of perinatal and intrapartum risk factors in the etiology of cerebral palsy in term deliveries in a Turkish population. J M atern Fetal Neonatal Med 2006;19:147-55.

18. Gosselin J, Gahagan S, A miel-Tison C. The A miel-Tison neurological assessment at term: conceptual and methodological continuity in the course of follow-up. M ental Retardation and Developmental Disabilities Research Reviews 2005;11:34-51.

19. A miel-Tison C. Update of the A miel-Tison Neurological assessment for the term neonate or at 40 weeks corrected age. Pediatr Neurol 2002;27:196-212.

20. Volpe JJ. Neurological examination: Normal and abnormal fetuses. In. N eurology of the newborn (4th edn). Philadel phia: WB Saunders, 2001;127.

21. Stahlmann N, Härtel C, K nopp A, Gehring B, K iecksee H, Thyen $U$. Predictive value of neurodevelopmental assessment versus evaluation of general movements for motor outcome in preterm infants with birth weights $<1500 \mathrm{~g}$. Neuropediatrics 2007; 38:91-99.

22. Triulzi $F$, Parazzini $C$, Righini $A$. Patterns of damage in the mature neonatal brain. Pediatr Radiol 2006;36:608-20.

23. Perlman JM, Risser M B, B royles RS. B ilateral cystic perivantricular leukomalacia in the premature infant: associated risk factors. Pediatrics 1996;97:822-27.

24. Pinto-M artin J, Riolo S, Cnaan A, Holzman C, Susser M V, Paneth N. Cranial ultrasound prediction of disabling and nondisabling cerebral palsy at age two in low birth weight population. Pediatrics 1995;95:249-54.

25. Vohr B, M ent LR. Intraventricular hemorrhage in the preterm infant. Early Human Development 1996;44:1-16.

26. Zupan V , G onzal es P, L acaze-M asmonteil T, B oithias C, d'A lest AM , D ehan M, Gabilan J C. Periventricular leukomalacia: risk factors revisited. D evelopmental M edicine and $C$ hild N eurology 1996;38:1061-67.

27. Seme-Ciglenecki P. Predictive values of cranial ultrasound and assessment of general movements for neurological development of preterm infants in the $\mathrm{M}$ aribor region of Slovenia. Wien $\mathrm{K}$ Iin Wochenschr 2007;119:490-96.

28. PerIman J M . Intrapartum asphyxia and cerebral pal sy: is therea link? Clin Perinatol 2006;33:335-53.

29. B racci $R$, Perrone $S, B$ uonocore $G$. The timing of neonatal brain damage. Biol Neonate 2006;90:145-55.

30. Stanojevic M. Three-dimensional (3D) ultrasound of neonatal brain. J Perinat M ed 2005;33 (suppl 1):41.

31. Stanojevic M, Hafner T, Kurjak A. Three-dimensional (3D) ultrasound-a useful imaging technique in the assessment of neonatal brain. J Perinat M ed 2002;30:74-83.

32. Stanojevic M , Pooh RK, K urjak A, K os M. Three-dimensional ul trasound assessment of the fetal and neonatal brain. Ultrasound Rev Obstet Gynecol 2003;3:117-30.

33. Enriquez G, Correa F, L ucaya J, Piqueras J, A so C, Ortega A. Potetntial pitfalls in cranial sonography. Pediatr Radiol 2003;33:110-17.
34. de V ries LS, G unardi $H, B$ arth PG, B ok LA, V erboon-M aciolek $M A$, Groenendaal $F$. The spectrum of cranial ultrasound and magnetic resonance imaging abnormalities in congenital cytomegal ovirus infection. N europediatrics 2004;35:113-19.

35. Haiden N, K lebermass $K$, Rucklinger $E, B$ erger $A$, Prusa AR, Rohrmeister K, W andl-V ergesslich K, K ohl hauser-V ollmuth C. 3-D ultrasonographic imaging of the cerebral ventricular system in very low birth weight infants. Ultrasound Med Biol 2005; 31:7-14.

36. Salerno CC, Pretorius DH, Hilton SW, O'B oyle M K, Hull A D, James GM, Riccabona M, M annino F, Craft A, Nelson TR. Three-dimensional ultrasonographic imaging of the neonatal brain in high-risk neonates: preliminary study. J UItrasound M ed 2000;19:549-55.

37. Riccabona $M, N$ elson $T R, W$ eitzer $C$, Resch $B$, Pretorius DP. Potential of three-dimensional ultrasound in neonatal and paediatric neurosonography. Eur Radiol 2003;13:2082-93.

38. M ercuri E, Dubowitz L, Paterson B rown S, Cowan F. Incidence of cranial ultrasound abnormalities in apparently well neonates on postnatal ward: correlation with antenatal and perinatal factors and neurological status. A rch Dis Child Fetal Neonatal Ed 1998; 79:F 185-9.44,48-60.

39. Levene M, Dowling S, Graham M, Fogelman K, Galton M, Philips M. Impaired motor function (clumsiness) in 5 year old children: correlation with neonatal ultrasound scans. Arch Dis Child 1992;67:687-90.

40. Einspieler C, Prechtl HFR, B os A F, Ferrari F, Cioni G. Prechtl's method on the qualitative assessment of general movements in preterm, term and young infants. M ac K eith Press, C ambridge, 2004.

41. Hadders-A Igra M. General movements: a window for early identification of children at high risk for developmental disorders. J Pediatr 2004;145: S12-S18.

42. Prechtl HFR. Qualitative changes of spontaneous movements in fetus and preterm infant are a marker of neurological dysfunction. Early Hum Dev 1990;23:151-58.

43. DeV ries J IP, V isser GHA, Prechtl HFR. The emergence of fetal behavior. Qualitative aspects. Early Hum Dev 1982;7:301-22.

44. Hadders-A Igra M, K lip-V an den N iewcendijk WJ, M artijn A, van Eyken L. A ssessment of general movements: towards a better understanding of a sensitive method to evaluate brain function in young infants. Dev M ed Child Neurol 1997;39:89-99.

45. B ekedam DJ, Visser GHA, de V ries JJ, Prechtl HFR. M otor behaviour in the growth retarded fetus. Early Human Development 1985; 12:155-65.9.

46. Cioni G, Prechtl HF. Preterm and early postterm motor behaviour in low-risk premature infants. Early Hum D ev 1990;23:159-91.

47. Seme-Ciglenecki $P$. Predictive value of assessment of general movements for neurological development of high-risk preterm infants: comparative study. Croatian M edical Journal 2003; 44:721-27.

48. Cioni G, Prechtl HFR, Ferrari F, Paolicelli PB, Einspieler C, Roversi M F. Which better predicts later outcome in full term infants: quality of general movements or neurological examination?. Early Hum Dev 1997;50:71-85.

49. Sival DA, Brouwer OF, Bruggink JL, VIes JS, StaalSchreinemachers A L, Sollie K M , Sauer PJ, Bos A F. M ovement analysis in neonates with spina bifida aperta. Early Hum Dev 2006;82:227-34. 
50. M azzone L, M ugno D, M azzone D. The G eneral M ovements in children with Down syndrome. Early H um Dev 2004;79:119-30.

51. Zuk L, Harel S, L eitner Y, Fattal-V al evski A. N eonatal general movements: an early predictor for neurodevelopmental outcome in infants with intrauterine growth retardation. J Child Neurol 2004;19:14-18.

52. Parisi P, Francia A, V anacore N, Fiore S, Giallonardo AT, $M$ anfredi M . Psychomotor development and general movements in offspring of women with epilepsy and anticonvul sant therapy. Early Hum Dev 2003;74:97-108.

53. Kurjak A, A zumendi $G, V$ ecek $N$, et al. Fetal hand and facial expression in normal pregnancy studied by four-dimensional sonography. J Perinat M ed 2003;31:496-508.

54. Kurjak A, Azumendi G. The Fetus in Three Dimensions. Imaging, Embryology and Fetoscopy. Informa Healthcare, London, 2007.

55. Kurjak A, Stanojevic M, A ndonotopo W, Salihagic-K adic A, Carera J M, A zumendi G. B ehavioral pattern continuity from prenatal to postnatal life - a study by four-dimensional (4D) ultrasonography. J Perinat M ed 2004;32:346-53.

56. Stanojevic $M$, Perlman $M$, Andonotopo $W, K$ urjak A. From Fetal to neonatal behavioral status. Ultrasound Rev Obstet Gynecol 2004;4:459-71.

57. Kurjak A, Stanojevic M, A zumendi G, Carrera J M. The potential of four-dimensional ultrasonography in the assessment of fetal awareness. J Perinat M ed 2005;33:46-53.

58. Sarnat HB. A natomic and physiologic correlates of neurologic development in prematurity. In Sarnat HB (Ed): Topics in neonatal neurology. New Y ork: G rune and Stratton 1984:1-24.

59. Sarnat HB. Functions of the corticospinal and corticobulbar tracts in the human newborns. J Pediatr N eurol 2003;1:3-8.

60. A miel-Tison C. Clinical assessment of the infant nervous system. In Levene MI, Chervenak FA, Whittle M (Eds): Fetal and Neonatal Neurology and Neurosurgery (3rd edn). Churchill Livingstone: London, 2001:99-120.

61. Salisbury AL, Duncan Fallone M, Lester B. N eurobehavioral A ssessment from F etus to Infant: the NICU N etwork Neurobehavioral Scale and the Fetal Neurobehavioral Coding System. M RDD Research Reviews 2005;11:14-20.

62. de V ries JIP, V isser GHA, Prechtl HFR. Fetal motility in the first half of pregnancy. In Prechtl HFR (Ed): Continuity of neural functions from prenatal to postnatal life. Clin Dev Med 94 Oxford, Blackwell, 1984:46-63.

63. K ostovic̀ I, Judaš M , Petanjek Z, Šimic G . O ntogenesis of goaldirected behavior: anatomo-functional considerations. International J ournal of Psychophysiology 1995;19:85-102.

64. K ostovic I, Seress L, M rzljak L, J udaš M. Early onset of synapse formation in the human hippocampus: a correlation with $\mathrm{N}$ isslGolgi architectonics in 15- and 16.5-week-old fetuses. Neuroscience 1989;30:105-16.

65. M utch L, A lberman E, Hagberg B, Kodama K, Perat M V. Cerebral palsy epidemiology: where are we now and where are we going? Dev M ed Child Neurol 1992;34:547-51.

66. B ax M, Goldstein M, Rosenbaum P, L eviton A, Paneth N, Dan $B$, Jacobsson $B$, Damiano $D$, Executive Committee for the Definition of Cerebral Palsy. Proposed definition and classification of cerebral palsy A pril 2005. Dev Med Child Neurol 2005;47:571-76.

67. Sankar C, M undkur N. Cerebral palsy-definition, classification, etiology and early diagnosis. Indian J Pediatr 2005;72:865-68.

68. Shapiro BK. Cerebral palsy: a reconceptualization of the spectrum. J Pediatr 2004;145 (suppl. 2):S3-7.

69. A miel-Tison C, GosselinJ, Infante-Rivard C. Head growth and cranial assessment at neurological examination in infancy. D ev M ed Child Neurol 2002; 44:643-48.

70. Pooh RK, Pooh K, Nakagawa Y, Nishida S, Ohno Y. Clinical application of three-dimensional ultrasound in fetal brain assessment. Croat M ed J 2000;41:245-51.

71. Campbell S, Lees C, M oscoso G, Hall P. U Itrasound antenatal diagnosis of cleft palate by a new technique: the 3D "reverse face" view. Ultrasound Obstet Gynecol 2005;25:12-8.

72. Pooh RK, Ogura T. N ormal and abnormal fetal hand positioning and movement in early pregnancy detected by three- and fourdimensional ultrasound. Ultrasound Rev Obstet Gynecol 2004;4:46-51.

73. DiPietro JA. N eurobehavioral assessment before birth. M ental Retardation and Developmental Disabilities R esearch R eviews 2005;11:4-13.

74. Kurjak A, M iskovic B, Stanojevic M, A miel-Tison C, A hmed B, A zumendi G, V asilj O, A ndonotopo W, Turudic T, SalihagicKadic $A$. N ew scoring system for fetal neurobehavior assessed by three- and four-dimensional sonography J Perinat Med 2008;36:73-81. 